Article

\title{
Adoption Drivers of Improved Open-Pollinated (OPVs) Maize Varieties by Smallholder Farmers in the Eastern Cape Province of South Africa
}

\author{
Masithembe Sigigaba ${ }^{1, *}$, Lelethu Mdoda ${ }^{2}\left(\mathbb{D}\right.$ and Asanda Mditshwa ${ }^{3}$ \\ 1 Department of Agricultural Extension and Rural Resource Management, University of KwaZulu-Natal, \\ Scottsville, Pietermaritzburg 3209, South Africa \\ 2 Department of Agricultural Economics, Agricultural Management and Agribusiness, University of \\ KwaZulu-Natal, Scottsville, Pietermaritzburg 3209, South Africa; MdodaL@ukzn.ac.za \\ 3 Department of Horticultural Science, University of KwaZulu, Scottsville, Pietermaritzburg 3209, South Africa; \\ mditshwaa@ukzn.ac.za \\ * Correspondence: 221116946@stu.ukzn.ac.za; Tel.: +27-78-687-5148
}

Citation: Sigigaba, M.; Mdoda, L.; Mditshwa, A. Adoption Drivers of Improved Open-Pollinated (OPVs) Maize Varieties by Smallholder Farmers in the Eastern Cape Province of South Africa. Sustainability 2021, 13, 13644. https://doi.org/10.3390/ su132413644

Academic Editor: Črtomir Rozman

Received: 25 August 2021

Accepted: 3 November 2021

Published: 10 December 2021

Publisher's Note: MDPI stays neutral with regard to jurisdictional claims in published maps and institutional affiliations.

Copyright: (c) 2021 by the authors. Licensee MDPI, Basel, Switzerland. This article is an open access article distributed under the terms and conditions of the Creative Commons Attribution (CC BY) license (https:// creativecommons.org/licenses/by/ $4.0 /)$.
Abstract: This study assesses the determinants of adoption drivers of improved open-pollinated (OPVs) maize varieties by smallholder farmers in the Eastern Cape Province of South Africa. Crosssectional data of multi-stage random sampling was used to randomly select 150 smallholder farmers in the province. Data collection was conducted through a well-structured questionnaire administered to 150 smallholder farmers. Descriptive statistics and a logistic regression model were used for the analyses. The inferential results reveal that the majority of farmers in the study area were females (70\%) with an average age of 45 years and had six people in the households. Smallholder maize farmers spent an average of 10 years in school. The results show that smallholder maize farmers had a farm size of 3 ha and a household income of R 3565.00, which contributes highly to household and farm operations. Farmers had access to extension services and were members of farm organizations. The results show that hybrid is the most used maize variety rather than OPVs. The main reason, among other things, for the poor use and adoption of OPVs is the lack of knowledge about the seeds. The results drawn from the estimations show that socio-economic and institutional factors influenced the adoption of OPVs by farmers in the study area. Therefore, the study recommends strengthening the existing extension services to highlight the benefits of OPVs through training and farmers' information days.

Keywords: adoption; Eastern Cape Province; open-pollinated variety (OPVs); smallholder farmers

\section{Introduction}

Agriculture is the backbone of many people in developing countries. The worlds population is expected to reach 10 Billion by 2050, thus putting pressure on food production to increase and to accommodate the growing population [1]. Enhancing crop production is considered essential for improving farmers' and peoples' welfare in these developing countries. This means that the control of agriculture as the primary source of food and job creation must be enhanced in developing countries as it is the only strategy to fight poverty and food insecurity [2]. Adopting improved maize varieties is seen as one of the approaches available to meet the worlds' consumption demand [3].

Maize (Zea mays) is also called corn and is the third most vital cereal crop after wheat and rice [2]. Maize is the most grown crop in many developing countries, especially SubSaharan Africa (SSA), contributing immensely to the SSA economy [2,3]. This cereal crop is an essential staple crop produced by most smallholder farmers and produced under diverse SSA environments [4]. Although commercial and resource-poor farmers have this crop, it is primarily dominated by resource-poor farmers in low-input environments. It is extensively consumed as a staple food by poor rural and urban households [5,6]. Maize occupies 
the largest land area of all staples in SSA; annual maize grain production is projected at nearly 72 million metric tons (MT) [4,5,7]. Maize covers about $45 \%$ of the cultivated area generating about $50 \%$ of rural cash income and employment in developing countries. The crop is used to make local drinks, soup, and livestock feed [8,9]. About $60 \%$ of the cropping area in South Africa is estimated to be planted with maize; this indicates that maize is the largest crop grown by smallholder farmers in the country [10]. Maize is generally grown in semi-arid regions of South Africa and is primarily rain-fed [10]. Production of maize is influenced by changing climatic patterns and farmers' planting intentions, particularly the need to produce output in surplus of their subsistence requirements. Droughts and floods destabilize crop yields and cumulative production by decreasing food availability and agricultural returns [11]. For example, in the past decade, growth in maize production has primarily been due to area increase rather than yield improvement $[8,12]$. As a result, this inhibits further investment on maize production and economic growth of SSA.

South Africa experiences several factors which affect maize production, such as low levels of education, agronomic challenges, credit accessibility, availability of the extension service, low per capita income, and little investment in production technology $[6,13]$. Change in climatic conditions is another critical factor that affects maize production, especially prolonged drought spells. Multi-year drought spells have occurred in the last decade and have reduced maize production [14]. Notably, Eastern Cape Province (ECP), is the poorest province out of the nine provinces in South Africa, and since 2015, this region has been affected severely by drought [14]. Since farmers in the province solemnly depend on rainfall for maize production, it suffers the most because of drought. $[15,16]$.

Increasing productivity is of urgent obligation for the maize industry, mainly smallholder farmers in developing countries. For instance, improved seed varieties that can withstand unfavorable climatic and soil factors might be instrumental in increasing productivity and yield. Enhancing crop production is considered necessary for improving the welfare of smallholder farmers whose livelihoods depend solely on farming through the development and improvement of agricultural practices and the availability of improved seed varieties. Adopting these high-yield varieties by large and smallholder farmers is expected to motivate increased crop production, which can ultimately assist in reducing poverty and increase rural household food security [17]. Using the improved maize varieties increases yield, consumption, and food security [18]. In a study conducted in Mexico, it was found that the adoption and use of hybrid maize had a positive impact on household welfare. A study conducted in Pakistan revealed that improved maize varieties' adoption had increased grain yield, farm returns, and food security [18]. In Malawi, improved maize varieties were found to have a positive effect as they increased crop yield, disease resistance, price advantage, storability, and market demand [19]. Improved maize varieties have been observed to sustain maize production, mainly under smallholder farming conditions [20]. The development of improved maize varieties continues to be a significant objective of improved maize programs and research institutes across the globe. If farmers adopt these improved OPVs, maize can provide considerable financial benefits through increased grain harvests and reduced risk.

The adoption of improved maize seed varieties has long been recognized to enhance crop yield and farm returns, thereby enabling crop diversification and enhanced market participation. Yet, surprisingly, the uptake and adoption of these varieties have been slow. This is because smallholder farmers in South Africa are resource-poor, making it hard to buy improved maize varieties such as OPVs and hybrid seeds [21]. As a result, farmers tend to use normal traditional seeds from their harvest, not enhancing crop production. The smallholder farmers use traditional varieties whose productivity is relatively low compared to the improved maize varieties. Adopting enhanced maize varieties is mainly due to less accessibility and high prices, resulting in lower maize production [22].

Multiple previous studies have been conducted on the estimation of the relationship between the inputs and output of agriculture $[23,24]$, while some studies determined the impact of climate change on crop productivity $[25,26]$. Moreover, studies have focused on 
the socio-psychological behavior of farmers to adopt improved technology $[27,28]$. However, limited studies have focused on the adoption drivers of improved open-pollinated maize varieties by smallholder farmers. Additionally, in South Africa, no study has focused on assessing the adoption drivers of improved maize varieties by farmers with the intention to enhance maize productivity and farm returns. Therefore, the current study covers the research gap and contributes to the existing literature on farmers' intention to use improved maize farmers in South Africa. Therefore, the current article aims to ascertain factors affecting the adoption of improved maize seed varieties (OPVs) in the Eastern Cape Province of South Africa. The remainder of this paper is organized as follows. The second section discusses the data and the methods used. This section is followed by the results and discussion. The last section concludes the study. The study hypothesis is that the driving factors of adoption of improved maize varieties by smallholder maize farmers are socio-economic and institutional factors.

\section{Conceptual Framework of Using OPVs by Smallholder Farmers}

Based on consumer behavior theory, smallholder farmers' use of new technology is influenced by countless factors, including technology, socioeconomic factors, policy, research, and institutional factors. Thus, it is necessary to understand these factors as technology innovation is vital in fast-tracking Sustainable Development Goals (SDGs), especially the first objective to eradicate all forms of poverty and malnutrition.

Farmers are faced with the uphill of producing more to meet the growing population, especially in developing countries. Moreover, farming is challenged by many factors such as weather conditions, lack of innovation, and transaction costs. The use of innovative practices is the only solution that farmers can use to improve their productivity and enhance farm returns. The adoption of improved maize varieties is observed as a link between various actors that enable the movement of information and seed to the farmer and then output from the farmer to the market in exchange for money to improve the standard of living [12]. Adopting technology is a self-motivated process and in the context of risky production, such as that of the agricultural sector, where production structure is essential as many people rely on agriculture for livelihoods generation [22]. However, to improve the productivity of the maize sector, the adoption of improved seeds should form part of the adoption of a technological package by smallholder farmers. Figure 1 below illustrates the conceptual framework of smallholder farmers' adoption of improved maize variety.

The adoption of agricultural technologies such as the OPV maize varieties is primarily constrained by many factors such as socioeconomic, institutional, external, social factors, and cultural contexts among smallholder farmers. This conceptual framework assumes that farmers' decisions to use improved maize seeds (OPVs) are influenced by socioeconomic factors (such as age, education, sex, and family size). It is further assumed that these farmers' factors and familiarity with the technology also play a significant role in influencing the decision of farmers to use OPVs. Furthermore, the institutional factors, characteristics of agricultural innovation, supportive policy, and external factors encourage farmers to use improved maize seed and other technologies that improve productivity.

With the assumption that farmers adopt the improved maize variety, it means the yields will improve, leading to increased crop productivity and farm returns. The main reason for adopting enhanced maize varieties (OPVs) are increased crop productivity and farm returns [23]. The adoption of improved maize varieties is a savior for most of the population in most parts of Africa that depend on agricultural production and yet live among drought-prone regions. This adoption increases crop productivity and farm returns. It further assists maize farmers and households in lessening food insecurity and alleviating poverty at the household level. 


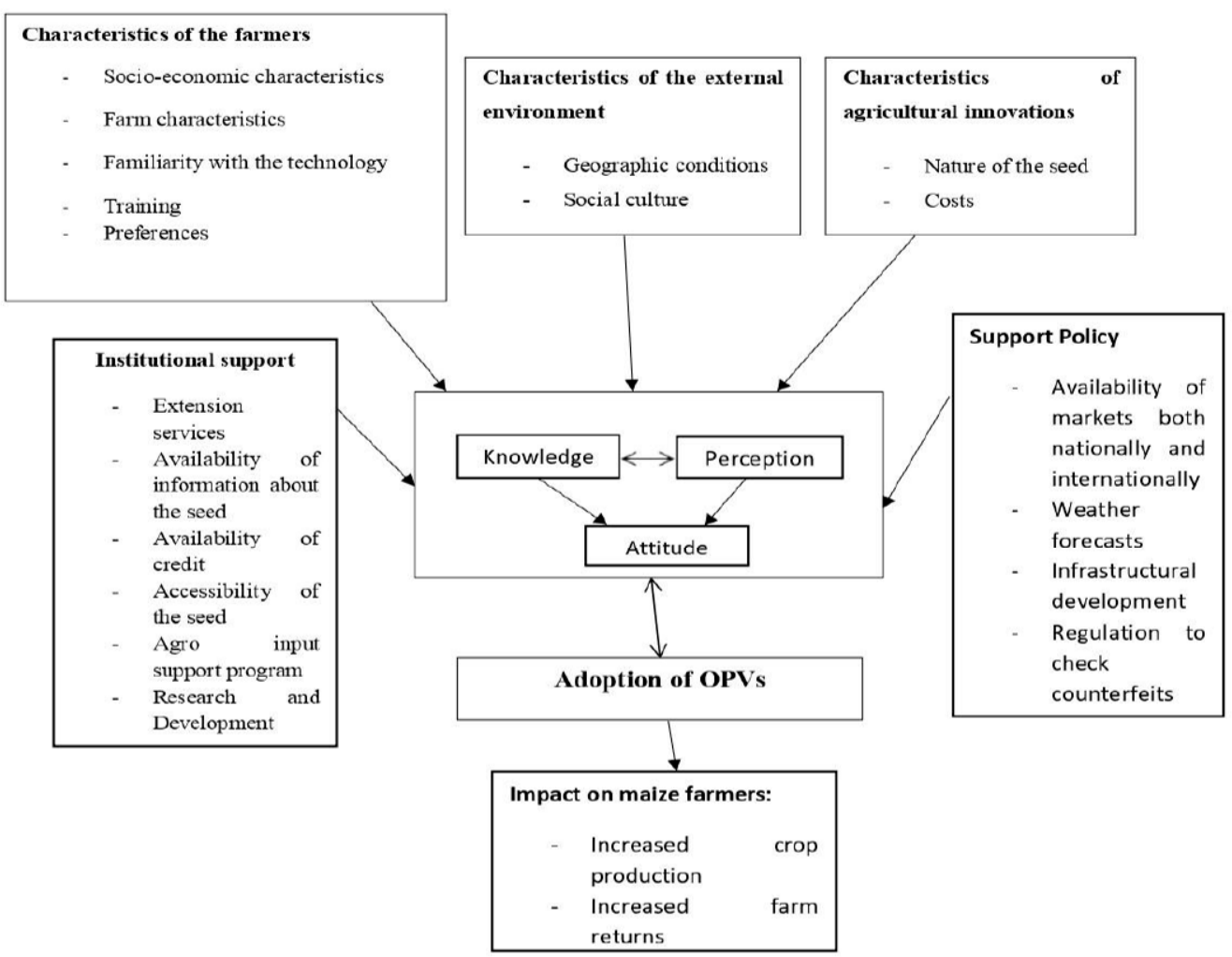

Figure 1. Conceptual framework of improved maize varieties (OPVs) by smallholder farmers.

Understanding drivers of improved maize variety adoption by smallholder farmers is crucial to developing policies for agricultural development and meeting the growing population. Several socio-economic and institutional factors may restrict the adoption of improved maize varieties by emerging maize growers [23,29]. Multiple previous studies at a global level have been conducted to focus on the relationship between the inputs and outputs of agriculture. In contrast, some studies focused on determining the impact of climate change on crop productivity. Moreover, studies conducted on the socio-psychological behavior of farmers have also been conducted to adopt improved technology. However, limited studies have focused on the adoption drivers of improved open-pollinated maize varieties by smallholder farmers.

Additionally, in South Africa, no study has focused on assessing the adoption drivers of improved maize varieties to enhance maize productivity and farm returns. Therefore, the current study covers the research gap and contributes to the existing literature on farmers' choice to use improved maize farmers in South Africa. Thus, the present article aims to ascertain factors affecting the adoption of improved maize seed varieties (OPVs) in the Eastern Cape Province of South Africa.

The remainder of this paper is organized as follows. The second section discusses the data and the methods used. The results and discussion follow this section. The last section concludes the study.

\section{Materials and Methods}

\subsection{Selection of the Study Area}

The study was conducted in the Eastern Cape Province, the third-largest Province in South Africa. The province has a population of 6,562,053, and the majority of the people reside in rural areas and derive their livings from practicing agriculture. The persistent poverty is the reason that this province lies below the poverty line [30,31]. The region presents an agricultural background (crop, vegetable, citrus, and livestock farming) spread with a trivial number of agro-industrial and eco-tourism infrastructures. 
Agricultural production is mainly practiced by smallholder farmers, although few commercial farmers primarily practice citrus farming. Smallholder farmers are mainly involved in agriculture for home consumption and agribusiness. Agricultural production is declining due to climate change, lack of credit, and ancient farming techniques. Sibanda et al. [21] and Mnkeni [32] agree that the province is characterized by smallholder farmers who are low-income and resource poor. The region is hit by persistent drought, which adversely affects agricultural productivity [33]. The use of improved open-pollinated maize varieties (OPVs) is one of the modern innovations which farmers in South Africa adopt to enhance productivity, improve food security, and alleviate poverty.

\subsection{Research Design}

The approach of this paper is an inquiry that involves the use of the quantitative approach. This approach played an important role in gathering empirical evidence on the nature of smallholders' adoption of improved open pollination maize varieties to increase farming participation in the economy. The research was mixed method at heart, thus allowing the researchers to draw a more holistic picture of the potentials of improved open pollination maize variety, factors influencing adoption, and challenges faced by farmers in using improved open pollination maize varieties. The study adopted a crosssectional research design where data were collected at one point on several variables such as demographics, household socioeconomic factors, and data on challenging factors in the adoption of improved open-pollinated maize varieties (OPVs).

\subsection{Sampling Techniques and Sample Determination}

The study was quantitative. A cross-sectional research design was used to collect data at one point in time. A multi-stage sampling procedure was employed in this study. The first stage was the selection of two District Municipalities where smallholder farming is more active, OR Tambo and Joe Gqabi District Municipalities. The second stage purposely selected four local municipalities based on their agricultural activities provided by agricultural extension officers. The last stage and final stage, random selection, was used to choose maize farmers. Smallholder maize farmers were the unit of analysis. The randomly selected maize farmers in the selected local municipalities were functional and enhanced farmers' livelihoods. These maize farmers were suitable for this study as they were situated in different municipalities and communities, as well as using different agricultural techniques. The sample size was 150 maize farmers.

\subsection{Data Collection}

A structured questionnaire was administered during single-visit interviews on respondents and was used as the primary data collection tool with the use home language, IsiXhosa. Questionnaires were arranged and distributed on a farmer-to-farmer basis. The questionnaire was pretested before it was finalized. Pretesting was conducted to improve the questionnaire and check on essential aspects such as the time taken to complete the questionnaire and the suitability and appropriateness of the questions. Time considerations were imperative in the questionnaire administration, given the level of farmer exhaustion in the study area. Pretesting was conducted in the same community with a few farmers who did not participate in the primary survey. Data collected were on farm characteristics, adoption of improved maize varieties, challenges faced in adopting, and factors hindering smallholder farmers' adoption of improved maize varieties. Primary data was collected from sample respondents who practiced maize farming through a structured interview schedule, which was intended to generate data on some individual, institutional, economic, and demographic variables, which are hypothesized to influence the adoption decision of the farming head on improved maize varieties. Additionally, information on the knowledge and attitudes on improved maize farmers, factors and risk affecting farmers decisions, and lastly, challenges faced by farmers in adopting the improved maize varieties. The structured questions were collected in the form of closed-ended questions where 
farmers were selecting from the options provided and open-ended questions where it was possible to allow farmers to further explain their answers. Data collected were on farm characteristics, adoption of improved maize varieties, challenges faced in adopting, and factors hindering adoption of improved maize varieties by smallholder farmers. Secondary data from published work, departmental information, and other research works conducted before were also used. Data collection was conducted by five well-trained enumerators in the Local Municipalities chosen. Table 1 describes the data, their measurement types, and their hypothesized relationship with the dependent variables. Data collection was conducted in September 2018.

Table 1. Definitions of primary variables and a priori expectations of collected data $(n=150)$.

\begin{tabular}{|c|c|c|c|}
\hline Variable & Description & Measurement & Expected Sign \\
\hline Adpt & $\begin{array}{l}\text { Adoption of improved maize } \\
\text { varieties by farmers }\end{array}$ & $\begin{array}{l}\text { Dummy, } 1 \text { = Adopting improved maize variety, } \\
\qquad 0=\text { otherwise }\end{array}$ & \\
\hline Gen & Gender of the farmers & Dummy, 1 = Male, $0=$ otherwise & + \\
\hline AGE & Age of the farmer & Continuous, Actual years & - \\
\hline TRSP & Transportation to markets & $\begin{array}{c}\text { Dummy, } \begin{array}{c}1=\text { have access to transportation to } \\
\text { markets, } 0=\text { otherwise }\end{array}\end{array}$ & - \\
\hline $\mathrm{HI}$ & Household income & Continuous & + \\
\hline YRSP & $\begin{array}{l}\text { Years spent in school by the } \\
\text { farmer }\end{array}$ & Continuous, Actual years & + \\
\hline FRMSZ & Farm size & Continuous & + \\
\hline FEXP & Farm experience by farmers & Continuous & + \\
\hline ACEXT & $\begin{array}{l}\text { A farmer having access to } \\
\text { extension personnel }\end{array}$ & $\begin{array}{c}\text { Dummy, } 1=\text { access to extension personnel, } \\
0=\text { otherwise }\end{array}$ & + \\
\hline FROM & $\begin{array}{l}\text { Membership of farm } \\
\text { organization by the farmer }\end{array}$ & $\begin{array}{l}\text { Dummy, } 1=\text { member of farm organization, } \\
0=\text { otherwise }\end{array}$ & + \\
\hline CA & Credit Access & $\begin{array}{c}\text { Dummy }=1 \text { if farmer } \\
\text { has access }\end{array}$ & + \\
\hline NFI & Non-farm Income & Continuous & - \\
\hline $\mathrm{DM}$ & $\begin{array}{l}\text { Distance to input market by } \\
\text { farmer }\end{array}$ & Continuous & - \\
\hline KOPMV & $\begin{array}{l}\text { Knowledge of open } \\
\text { pollination maize variety }\end{array}$ & $\begin{array}{c}\text { Dummy, } 1 \text { = farmer with knowledge of OPMV, } \\
0=\text { Otherwise }\end{array}$ & + \\
\hline FPD & $\begin{array}{l}\text { Farmer perception on drought } \\
\text { resistance }\end{array}$ & $\begin{array}{l}\text { Dummy, } 1=\text { Farmer perception on drought } \\
\text { resistance, } 0=\text { otherwise }\end{array}$ & + \\
\hline
\end{tabular}

The collected data were entered into Excel and were analyzed using STATA 15. The study applied descriptive statistics and inferential analysis to investigate knowledge of improved open-pollinated maize varieties (OPVs) and challenges smallholder farmers face. A Logit regression model was employed to estimate the factors influencing the adoption of open- maize varieties by smallholder farmers in the study.

\subsection{Descriptive Statistics and Inferential Analysis}

Descriptions of the variables used in the logistic regression model to show the knowledge of improved open pollination of maize varieties and challenges faced by smallholder farmers were performed using descriptive statistics and t-statistics. The results of this analysis were presented using frequency tables, cross-tabulations, and graphs. For continuous variables, mean and standard deviations were reported, while for categorical variables, percentages were reported.

\subsection{Analytical Analysis}

The study used Logit regression to determine the factors that have significant influence on the smallholder adoption of improved open-pollinated maize varieties (OPVs) in the study area. This method was chosen because it is a standard analysis method when the outcome variable is dichotomously measured as having a value of 1 or 0 , where $1=$ adopted 
OPVs and $0=$ not adopted OPVs. Logit regression is advantageous because it estimates the dichotomous outcome variables, which are more straightforward and flexible to make results more meaningful for interpretation [34,35]. $X_{i}$ represents the set of parameters which influence the adoption of open pollination of maize variety of the farmer.

This model was employed because it accommodates two categories in the dependent variable. It can resolve the heteroscedasticity problem, and it pleases the cumulative normal probability distribution $[34,36]$. Hence, the logistic model was selected for this study. Let $\pi_{i}$ be the probability of success. Additionally, consider $x=\left(x_{1}, x_{2}, \ldots, x_{n}\right)$ as a set of explanatory variables which can be discrete, continuous, or a combination of both discrete and continuous. Then, the logistic function for $\pi \mathrm{i}$ is given by Equation (1):

$$
\log \text { it } \pi_{i}=\log \left(\frac{\pi_{i}}{1-\pi_{i}}\right)=\beta_{0}+\beta_{1} x_{1}+\beta_{2} x_{2}+\beta_{3} x_{3}+\cdots \ldots+\beta_{n} x_{i, n}
$$

where:

$$
\pi_{i}=\frac{\exp \left(\beta_{0}+\beta_{1} X_{1}+\beta_{2} X_{2}+\beta_{3} X_{3}+\cdots \ldots+\beta_{n} X_{i, n}\right)}{1+\exp \left(\beta_{0}+\beta_{1} X_{1}+\beta_{2} X_{2}+\beta_{3} X_{3}+\cdots \ldots+\beta_{n} X_{i, n}\right)}=\frac{\exp \left(x^{\prime}{ }_{i} \beta\right)}{1+\exp \left(x^{\prime} \beta\right)}=\wedge\left(x^{\prime}{ }_{i} \beta\right)
$$

Here, $\pi_{i}$ denotes the probability that a sample is in a given category of the dichotomous response variable, commonly called as the "success probability" and, clearly, $0 \leq \pi_{i} \leq 1$. $\Lambda($.$) is the logistic cdf, with \lambda(z)=e^{z} /\left(1+e^{-z}\right)=1 /\left(1+e^{-z}\right)$, and $\beta$ represents a vector of parameters to be estimated (Joshi and Dhaka, 2021). The expression $\left(\frac{\pi_{i}}{1-\pi_{i}}\right)$ is called the odds ratio or relative risk.

\section{Estimation and Likelihood Ratio Test}

Maximum likelihood is the preferred method to estimate $\beta$ since it has better statistical properties, although we can use the least-squares approach. Consider the following logistic model with the single predictor variable $X$ given by the logistic function of:

$$
\pi(X)=\frac{\exp \left(x^{\prime} \beta\right)}{1+\exp \left(x^{\prime}{ }_{i} \beta\right)}
$$

We wish to find the estimates such that plugging $\beta^{\wedge}$ into the model for $\pi(X)$ gives a number close to 1 for all subjects who have adopted improved maize varieties and 0 otherwise. Mathematically, the likelihood function is given by Equation (4):

$$
L\left(\beta_{0}, \beta_{1}\right)=\prod_{i: Y_{i=1}} \pi\left(x_{i}\right) \prod_{i^{\prime}: Y_{i^{\prime}=0}}\left(1-\pi\left(x_{i^{\prime}}\right)\right)
$$

The estimates of $\beta^{\wedge}$ are chosen to maximize this likelihood function. We take the logarithm on both sides to calculate and use the log-likelihood function for the estimation purpose. We used the likelihood ratio to test if any subset of estimates $\beta$ is zero. Suppose that $p$ and $r$ represent the number of $\beta$ in the full model and the reduced model, respectively. The likelihood ratio test statistic is given by Equation (5):

$$
\wedge *=2\left[l\left(\beta^{(0)}\right)-l(\beta)\right]
$$

where $l\left(\beta^{\wedge}\right)$ and $l\left(\beta^{\wedge(0)}\right)$ are the log likelihoods of the full model and the reduced model, respectively, evaluated at the maximum likelihood estimation (MLE) of that reduced and $\Lambda * \sim \chi 2 n-r ; n$ and $r$ are the number of parameters in the full and the reduced model, respectively.

Adoption of agricultural technology occurs when the predictable utility from the technology exceeds that of non-adoption. Since utility is not observable, single or multivariate limited dependent models have been a workhorse for estimating factors affecting adoption. Adoption involves factors that are normally beyond the control of farmers, such as policy, 
institutional and environmental factors, as well as household endowments, the agricultural business opportunities available, and the nature of the technology itself. Furthermore, some of the factors that influence the continued use of the technology are associated with the user's experience in using it; the more farmers become knowledgeable to the use of a technology, the more they are likely to keep on using it. These phenomena generate modelling problems related to self-selection and endogeneity. The binary nature of values of the response variable decision narrow down our choice of analytical method to probit, binary and logit regression options.

The Logit was selected because of its capacity to better answer our main research questions and because of our data and sample characteristics (association between variables, slope tells how the log odds ratio in favor of adoption of improved maize varieties changes as independent variable change). Additionally, the significant explanatory variables do not have the same level of impact on the adoption decision of farmers. The relative effect of a given quantitative explanatory variable on the adoption decision is measured by examining adoption elasticity, which is why Logit is the most suitable model to be used. The variables that were assumed to influence the adoption decision of improved maize varieties were tested for multicollinearity. The Logit model was used as it offers the possibility to save the predicted variables used to estimate drivers of adoption automatically. Logit fits this type of study due to the cumulative nature of the variables used in the study since they assume a cumulative normal distribution, which leads to efficient estimators. This model characterizes adoption by the sample farmers so that it allows maximum likelihood estimation.

\subsection{Reliability and Validity}

Triangulation was used in this paper to identify similarities and differences in the data collected from respondents via interviews and observations, thus improving the reliability of the study findings and interpretations. A face validity of the questionnaire was confirmed by a panel of experts in Department of Agriculture, Agricultural Extensionist, Community Leaders, 2 Academic staff, and Research experts. To ensure the reliability of the questionnaire, a split half technique was used to determine the reliability coefficient with $\mathrm{R}=0.68$. The questionnaire was tailored to the needs of the subjects to whom it was intended (Bless and Higson-Smith, 2000). Their recommendations and amendments were incorporated into the final questionnaire used for data collection in the study. An updated list of smallholder maize growers was obtained from Department of Agriculture and Farm Organizations, thereby managing farmer error. Farmers who appeared on the list yet were no longer growing maize were removed to control for selection error.

\section{Results}

This section is divided into four sections, wherein the first section will concentrate on descriptive statistics, while the second part deals with challenges and types of improved maize varieties, third sections deals with an econometric analysis of the drivers to adopt the improved open pollination maize variety and last section deals with discussion of results. This section looks at confirming or rejecting the hypothesis of the study. The study hypothesis is that the driving factors of adoption of improved maize varieties by smallholder maize farmers are socio-economic and institutional factors.

\subsection{Socioeconomic Characteristics of Smallholder Farmers}

Table 2 shows the farm characteristics of smallholder maize farmers. Socioeconomic characteristics of maize farmers in the study area were presented as categorical and continuous variables. Out of the sample of 150 smallholder maize farmers, only $46 \%$ were adopters, while $54 \%$ were non-adopters. It was also found that most maize farmers prefer to use a hybrid maize variety rather than OPVs due to their availability in supermarkets compared to OPVs, which are not readily available. The study results reveal that most maize farmers were female, with a proportion of $70 \%$ and an average age of 45 years. 
These results agree with those of Sibanda et al. [21] and Katengeza et al. [37] that maize is primarily produced by female farmers who play an essential role in maize projects and home gardens. This result was also in line with Chandio and Jiang [17], who found that the average age of maize farmers was 42 years with formal education. Smallholder maize farmers spent an average of 10 years in school, which is equivalent to secondary education. Thus, it makes maize farmers literate as they can read and write, which was imperative for adopting innovative maize varieties. Moreover, $54 \%$ of smallholders were married and had an average family size of six people per household, which played a crucial role in farming by providing family labor. Most maize farmers were full-time farmers, at $76 \%$, as they rely solely on agriculture to live and derive livelihoods. These results were in line with Kakuru [12], who found that smallholder maize farmers generally derived their livelihoods from agricultural production.

Smallholder farmers had a farm size of 3 ha with an average of 13 years of farming experience. Smallholder maize farmers had a household income of R 3565.00, which contributes highly to household and farm operations. One of the significant constraints faced by maize farmers is access to credit, with $78 \%$ stating they do not have access to credit. Farmers had access to extension services, at $70 \%$, and $75 \%$ were members of farm organizations. Most of the maize farmers traveled more than $30 \mathrm{~km}$ to access input markets to purchase the improved variety, and maize farmers were aware of their high yields from the improved maize variety. The ratio of OPV seed availability in the market was $1 \%$, which agrees with the above results of the low adoption of OPVs as they are not available in the market.

Table 2. Farm characteristics.

\begin{tabular}{|c|c|c|c|}
\hline Characteristics & Frequency $(n)$ & Percentage (\%) & SD \\
\hline $\begin{array}{l}\text { Adopted improved maize varieties } \\
\text { Yes }\end{array}$ & 69 & 46 & 2.25 \\
\hline No & 81 & 54 & \\
\hline $\begin{array}{l}\text { Improved maize varieties } \\
\text { HYBRID }\end{array}$ & 99 & 66 & 1.35 \\
\hline OPVs & 51 & 34 & \\
\hline $\begin{array}{l}\text { Gender } \\
\text { Male }\end{array}$ & 45 & 30 & 0.49 \\
\hline Female & 105 & 70 & \\
\hline $\begin{array}{l}\text { Access to extension services } \\
\text { Yes }\end{array}$ & 105 & 70 & 0.66 \\
\hline No & 45 & 30 & \\
\hline $\begin{array}{l}\text { Member of Farm organization } \\
\text { Yes }\end{array}$ & 112 & 75 & 1.67 \\
\hline No & 38 & 25 & \\
\hline $\begin{array}{l}\text { Access to credit } \\
\text { Yes }\end{array}$ & 20 & 13 & 1.58 \\
\hline No & 130 & 87 & \\
\hline Characteristic & Mean & Std. dev & \\
\hline Age of the farmer & 45.12 & 10.45 & \\
\hline Family size & 6.32 & 4.63 & \\
\hline Farm size & 3.20 & 1.84 & \\
\hline Experience in growing maize & 12.65 & 7.15 & \\
\hline Years spent in school & 10.43 & 8.79 & \\
\hline Household income & 3565.00 & 34.59 & \\
\hline Distance to market outlets & 30.23 & 18.34 & \\
\hline OPVs seeds availability in the market & 0.939 & 0.239 & \\
\hline
\end{tabular}

\subsection{Types of Improved Maize Variety Used by Smallholder Farmers}

Maize is a widely produced staple crop grown by the majority of smallholder farmers. Farmers produce maize as it is easy to grow and can be grown even in harsh conditions given the changes that African countries face with prolonged drought, causing a decline in 
agricultural output. Figure 2 shows the improved maize varieties grown by smallholder farmers in the study area.

\section{Types of improved maize seeds varieties used by farmers}

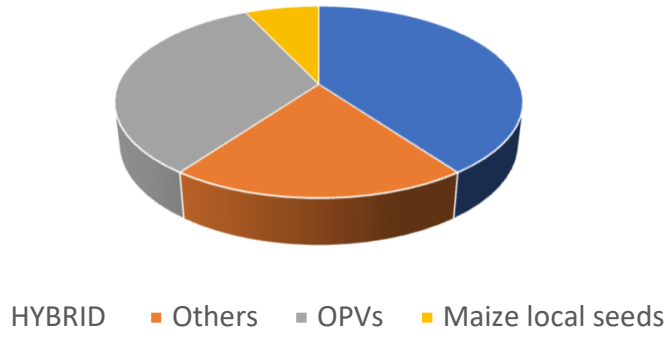

Figure 2. Types of improved maize seeds variety used by smallholder farmers.

The above results in Figure 2 reveal that the most commonly used improved maize seed variety types were HYBRID, OPVs, and others. HYBRID is the most used and adopted improved maize seed variety, and most farmers specified that this variety is primarily available in the markets. This type of improved maize variety is widely grown because farmers use it to feed livestock. Most of the adopted improved maize varieties were used for market purposes and home consumption by smallholder farmers. OPVs were the second most used improved maize variety, but farmers argue that this type of improved maize variety is not readily available to the markets, and there is a lack of knowledge about this variety of maize. Lastly, local seeds were the least used maize variety with $7 \%$, and many farmers complain of poor yield in using this type of maize variety.

\subsection{Challenges in Using OPVs by Smallholder Farmers}

Smallholder farmers find it hard to use OPVs on their farms. The results in Figure 3 show that the biggest challenge smallholder farmers face in accessing OPVs is that they do not find them in the local markets where they purchase their agricultural inputs. This has constrained farmers negatively as they have to look elsewhere for the improved maize varieties. The unavailability of OPVs in local markets leads to the cost of seed being high, resulting in farmers not purchasing it as they are constrained by finances on their own. A lack of knowledge and the high cost of labor were also found to deprive farmers in the study area. Maize production is labor-intensive, meaning that practicing maize farming requires an increased number of laborers [5]. These findings are in line with Kadafur et al. [5], who found that this type of maize variety is not found in local stores. It is costly and labor-intensive as a result and constrains many smallholder farmers as they will need additional labor, and they have an average of six persons in a household. Farmers find it hard to differentiate between hybrid local variety and OPVs, resulting in many farmers using hybrid local varieties on their farms. Farmers found that using OPVs uses more labor, which is costly to farmers. This is because maize production is labor-intensive and using OPVs requires additional labor, which smallholder farmers cannot afford due to financial constraints. Lack of finances was the challenge that made smallholder farmers not use OPVs as they were costly. This result is consistent with Da Encarnação Tomo and Zwane [3], who indicated that farmers do not use the OPVs to improve maize variety due to a lack of finance as they do not have financial support and rely on government securities to finance their farming. Farmers lack the finances to purchase maize seeds (OPVs) on the market. Lastly, the poorly labeled maize package caused many smallholder farmers not to use the OPVs. These results were in line with Fisher et al. [4] and Lunduka [20], who also found that significant barriers to adoption of improved maize (drought tolerant: DT) 
in Eastern and Southern Africa include the unavailability of improved seed, inadequate information and resources, high seed price, and farmers' perceptions of various attributes.

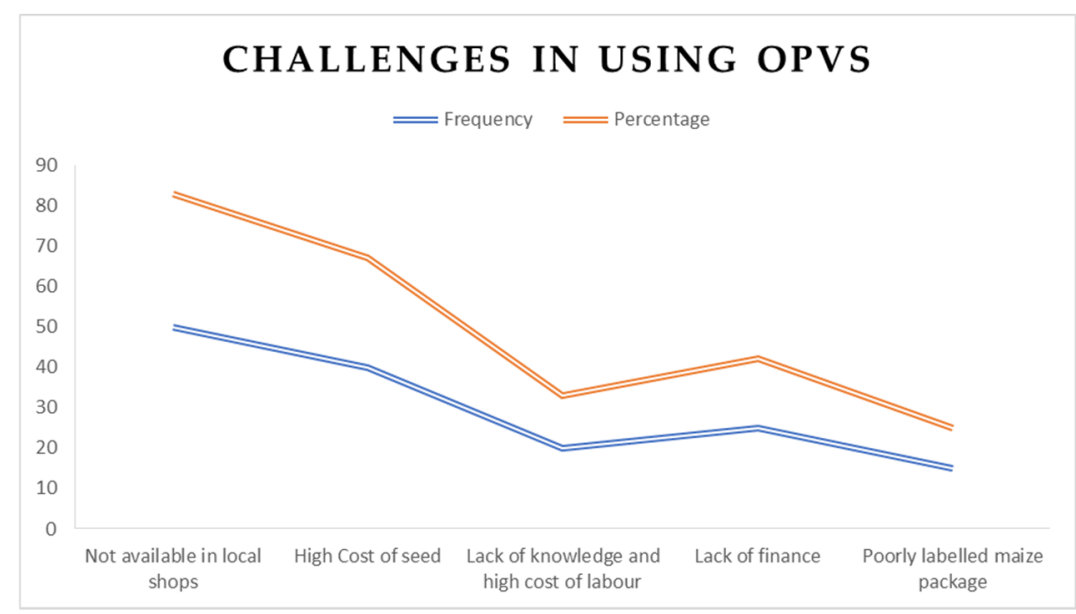

Figure 3. Challenges faced by smallholder farmers in using OPVs.

\subsection{Factors Affecting Smallholder Farmers' Decision to Adopt OPVs}

The study used Logit regression to estimate the factors influencing the adoption of improved open-pollinated maize varieties (OPVs) by smallholder farmers. The model results from Table 3 indicate that 16 variables included in model 7 were found to significantly affect the adoption of improved open-pollinated maize varieties (OPVs) by smallholder farmers at different probability levels. The details of significant variables from this model are shown in Table 4 and discussed as follows. The adjusted $R^{2}$ of the regression was 0.643 , which means that $64 \%$ of the variation in the dependent variable can be explained by the regressors present in the model. The higher the $\mathrm{R}^{2}$ value, the more explanatory the model is and the better it fits the sample. Table 3 illustrates the factors influencing the adoption of OPVs by smallholder farmers.

Table 3. Factors affecting the decision to adopt OPVs by smallholder maize farmers.

\begin{tabular}{|c|c|c|c|}
\hline Variables & Coefficient $(\beta)$ & $P>|z|$ & Odds Ratio $(\operatorname{Exp} \beta)$ \\
\hline Extension Services & 1.8791 & $0.003^{* * *}$ & 7.931 \\
\hline Years spent in school & 0.7954 & $0.027^{* *}$ & 0.517 \\
\hline Distance to markets & -0.542 & $0.034^{* *}$ & 1.719 \\
\hline Household income level & 0.0002 & $0.000 * *$ & 1.0002 \\
\hline Gender of the farmer & -0.944 & $0.043^{* *}$ & 2.569 \\
\hline $\begin{array}{l}\text { The area under cultivation of OPVs } \\
\text { (Farm size) }\end{array}$ & 0.345 & $0.028^{* *}$ & 1.413 \\
\hline $\begin{array}{l}\text { Perception factor for accepting } \\
\text { improved seeds: OPVs }\end{array}$ & 3.735 & $0.011^{* *}$ & 41.868 \\
\hline $\begin{array}{l}\text { Unavailability of OPVs in local } \\
\text { shops }\end{array}$ & -0.283 & $0.018^{* *}$ & 1.323 \\
\hline \multicolumn{4}{|c|}{$\begin{array}{l}\text { Number of observations } 150 \text { Log likelihood }-36.481983 \\
\text { LR chi2 (9) } 56.53^{* * *} \text { Prob }>\text { chi2 }=0.0000 \text { Pseudo } R^{2} 0.643\end{array}$} \\
\hline
\end{tabular}

As hypothesized, the frequency of extension services positively and significantly influenced the adoption of OPVs varieties at a $1 \%$ probability level. The odds-ratio in favor of adopting improved maize varieties, the other factors being kept constant, increases by a factor of 7.931 with the farmer having access to extension services compared to those who do not have it. The odds-ratio in favor of adopting improved maize varieties, other factors being kept constant, increases by a factor of 7.931 with the change in extension services by additional visits. This implies that farmers with access and contact with extension services each month are more likely to adopt the improved maize varieties than farmers 
with no access. These results are in line with Da Encarnacao and Zwane [3], Teshom and Tegegne [38], Gidi et al. [39], and Sibanda et al. [16] who found that farmers who have access to agricultural extension services are more likely to receive extension support and training that might increase the farmers' use of modern technologies and varieties which are trying to address farming needs and enhance output.

The number of years spent in school positively affects the adoption of OPVs by farmers and was significant at a 5\% level. This implies that the higher the number of years spent on formal education, the greater the chance of adopting improved maize variety as a production technology by farmers. The odds-ratio in favor of adopting improved maize variety, with the other factors kept constant, increases by a factor of 0.517 for the farmer who assumed that farmer's heads become literate than those who did not. This implies that educated farmers are more likely to adopt improved maize variety than not educated. This result is consistent with Kadafur et al. [5], Jaleta et al. [40], and Oluwayemisi et al. [41], who found that more educated farmers will readily adopt the new maize varieties (OPVs) as they have more knowledge and information than those with less education. This is because of access to information and awareness fetched by farmers' education as it increases the capacity to adapt and use innovation to enhance farm returns and yields.

The area under cultivation of OPVs was found to be significant at $5 \%$ and had a positive effect on the adoption of OPVs as improved maize variety by farmers. The odds ratio indicated in the model concerning the area under cultivation of OPVs implies that other thing being held constant, the odds ratio in favor of adopting improved maize variety increases by a factor of 1.413 as farmers cultivate OPVs. This implies that a unit of improved maize cultivated area is increased within the farm, strengthening the positive multiplier effects in the adoption of OPVS by farmers. The area under cultivation was found to be correlated to the adoption of modern technology. These results agree with Jaleta et al. [40], Chandio and Jiang [17], Mutanyagwa [42], and Subedi et al. [43], who stated that farmers with big farm sizes are willing to take risks connected with the adoption of modern technology to improve their yields and farm returns.

Household income positively affected the adoption of improved maize variety and was significant at $1 \%$. This result implies that the higher the household income of respondents, the greater the probability of adopting modern technologies and improved maize varieties among farmers in the study area. The odds-ratio favoring the adoption improved maize variety, other factor kept constant, increases by a factor of 1.0002 as household income increase by one unit of South African rand. This implies that a farmer with a better income will be more likely to adopt improved maize varieties. These results are consistent with Kadafur [5], Sibanda et al. [16], and Ketema and Kebede [44] who found that this is because of high household income, which results in the greater purchasing powers of the respondents and thus resulting in investing in modern technologies as a strategy to enhance production and farm returns. Additionally, more farmers have other incomes that contribute towards household income (salaries, agricultural income, remittances, and social securities).

The perception factor for accepting improved seeds has a positive effect on the adoption of OPVs as improved maize variety and was significant at 5\%. The odds-ratio in favor of adopting improved maize variety, other factors kept constant, increases by a factor of 41.868 as maize farmer knowledge increases by $1 \%$. This is because the adoption rate of OPVs is increased when farmers have a positive perception of improved maize variety. These results are in line with Sanchez-Toledano [22], who found that having positive attitudes by farmers positively influences the decision to adopt to better their farm income with improved market receiving of their products and higher productivity.

The gender of the farmers has a negative effect on the adoption of improved maize variety and was significant at the $5 \%$ level. This suggests that a unit increase of $1 \%$ in the gender of the farmers will induce a decrease in the adoption of OPVs by farmers in the study area. The odds-ratio in favor of adopting improved maize varieties, other factors being kept constant, decreases by a factor of 2.569 with the change in gender of the head 
from female to male. This further means that female farmers are more conscious about the technology to be accepted on their farms as compared to male counterparts. The positive sign implies that female-headed households tend to adopt the varieties more than their male counterparts. These results agree with Nigatu et al. [19] that male-headed farms have higher chances of accessing information and agricultural resources than female household heads. This puts female-headed farmers at a disadvantage in adopting modern technology as they lack knowledge and access to other agricultural resources.

Distance to markets has a negative effect on the adoption of improved maize variety and was significant at a 5\% level. This suggests that an additional kilometer to the distance traveled to access markets by farmers will decrease the adoption of OPVs. The farther farmers are from markets means that there will be less access to production inputs and a higher probability of obtaining up-to-date market information, and hence access more information about improved technology. The odds-ratio in distance favors adopting improved maize variety decreases by a factor of 1.719 as the market distance increases by one kilometer. The implication is that the longer the distance between farmers' residence and the market center, the lower the chances are of the farmer adopting the improved maize variety. These results are consistent with Kadafur [5], Teshom and Tegegne [38], and Nigatu et al. [19], who found that the longer the distance between farmers' houses and the market centers, the lower the probability will be to adopt OPVs as an improved maize variety.

The unavailability of OPVs in local shops has a negative effect on the adoption of improved maize varieties and was significant at 1\%. The results infer that the more the improved maize OPV seeds are unavailable on the market, the smaller their demand is, which forces farmers to opt for improved maize varieties available in the market. The odds-ratio indicated in the model concerning the unavailability of OPVs implies that, other things being held constant, the odds-ratio in favor of adopting improved maize variety decreases by a factor of 1.325 as farmers have no access to OPVs. These results agree with Sibanda et al. [16], who found that this unavailability of OPVs has contributed to low use by farmers as they tend to opt for the available improved maize variety.

\section{Marginal Effect Analysis}

The adoption of improved maize varieties is likely to be influenced by several socioeconomic and institutional characteristics of the maize farmers. Table 4 reports the results of the marginal effects analysis. The findings of the marginal effects estimation display that extension services, years spent in school, household income level, farm size, and the perception factor for accepting improved seeds (OPVs) positively influence the adoption rate of improved maize varieties, while the gender of the farmer, the distance to markets, and the unavailability of OPVs in local shops negatively influenced the adoption rate of improved maize varieties in the study area. The marginal coefficients of extension services are $\left(\beta_{2}=0.0279\right)$, which implies that after a 1 percent increase in extension services, the probability of adopting improved maize varieties will increase by 0.0279 percent. The marginal coefficient of years spent in school is $\left(\beta_{3}=0.0082\right)$, which implies that after a 1 percent increase in years spent in school, the probability of adopting improved maize varieties will increase by 0.0082 percent. Likewise, the coefficient of household income is $\left(\beta_{4}=0.0055\right)$; this implies that after a 1 percent increase in household income, the adopting probability of the maize grower would increase by 0.0081 percent. Finally, the coefficient of the perception factor for accepting improved seeds of OPVs is $\left(\beta_{4}=0.0186\right)$.

Furthermore, the coefficient of the farm size is $\left(\beta_{5}=0.0172\right)$; this result implies that after a 1 percent increase in farm size, the adoption probability of the maize grower would increase by 0.0172 percent. The coefficients of the gender of the farmers, distance to markets, and unavailability of OPVs in local shops were negative and significant. These results imply that with a 1 percent increase in these variables, the probability of adopting improved maize varieties will reduce by $0.0016,0.0007$, and 0.0184 percent, respectively. 
Table 4. Determining adoption of improved maize varieties (Marginal Effect).

\begin{tabular}{ccc}
\hline Variable & Marginal Effect & $P>\mathbf{z}$ \\
\hline Extension Services & $0.0279(0.0546)$ & $0.000^{* * *}$ \\
Years spent in school & $0.0082(0.0045)$ & $0.005^{* * *}$ \\
Distance to markets & $-0.0007(0.0049)$ & $0.023^{* *}$ \\
Household income level & $0.0055(0.0026)$ & $0.006^{* * *}$ \\
Gender of the farmer & $-0.0016(0.0082)$ & $0.015^{* *}$ \\
The area under cultivation of OPVs (Farm size) & $0.0172(0.0047)$ & $0.011^{* *}$ \\
Perception factor for accepting improved seeds: OPVs & $0.0086(0.0041)$ & $0.010^{* *}$ \\
Unavailability of OPVs in local shops & $-0.0184(0.0745)$ & $0.016^{* *}$ \\
\hline$* *$ and ${ }^{* *}$ are statistically significant at 1 and 5 levels, respectively. & &
\end{tabular}

\section{Discussion}

This paper sought to analyze the determinants of adoption drivers of improved open-llinated (OPVs) maize varieties by smallholder farmers in the Eastern Cape Province of South Africa. This was achieved by first estimating descriptive statistics to profile the farmers, their knowledge, the types of improved maize varieties they used, and the challenges they faced, taking Logit regression into effect to estimate the drivers of adoption of improved maize varieties. To achieve all these objectives, the study made use of crosssectional research design and collected data through the use of structured questionnaires, which captured all the required details.

The descriptive results showed that farmers are aware of the improved maize varieties and their usage, but adoption of OPVs is lower as the majority of the farmers opted for hybrids. This was associated with the fact that the hybrid variety is availability in supermarkets as compared to OPVs, which are not easily available. Farming in the province is practiced by female farmers, with an average age of 42 years. This is due to the fact that females are the ones who are left behind to take care of their families while their male counterparts are working in the corporate world and assist with financial backing. The majority of these females are involved in maize projects and home gardens, which supply their household for household consumption and surpluses for income generation. Family size was used as a proxy for family labor as they had an average of six people per household, and they were helping when it comes to farming as well as sharing information. Maize farmers were literate as they spent 10 years in school, which plays a crucial role in assessing the agricultural information and innovative techniques which are used in farming. Additionally, education made it easy for farmers to use and adopt different improved maize varieties available at their disposal. The majority of farmers were full time farmers, which made it easy to know what exactly their farm needs in order to enhance productivity and withstand the changing weather conditions. They farm at 3 ha, which is reasonable for smallholder farmers, and they derive their livelihoods from farming. This farm size is very efficient if it is utilized right by farmers. Farmers were relying on social grants, income generated from surpluses, and remittances to operate their farming business. Maize farmers had access to extension services and were members of farm organization which was beneficial to them in terms of providing training, sharing new information, providing market information, and new inputs being used to enhance agricultural output.

The results reveal that farmers in the study area were using three types of improved maize varieties, namely, hybrid, OPVs, and local seeds. The hybrid variety was widely used as farmers were able to obtain them in local supermarkets and were affordable to them, while OPVs were also used but at a lower rate due to their unavailability and higher price. Local seeds were also used, but their yield was very low compared to these two types of improved maize varieties.

Farmers face challenges in using OPVs in the study area and this affected their adoption rate of this type of improved maize varieties. The main challenges were that OPVs were not easily available to local markets where farmers reside and made it hard to be used. This led OPVs to be sold at high costs, which limited the majority of maize farmers as they 
cannot afford them as they lack financial support since depends on social securities for farm operations and take care of the households. Other challenges which constrain farmers are lack of knowledge and high cost of labor. Many farmers who do not use the OPVs lacked knowledge when it comes to them, and they were unable to differentiate OPVs and hybrid, which ultimate results in them selecting hybrid. Additionally, the mentioned cost of labor required for this type of improved maize varieties forces them to look for cheaper and easier-to-use types. Lack of finances made it hard for farmers to use OPVs, as they are expensive and cannot afford them. The poor labelling of these improved maize varieties is another challenge faced by smallholder farmers.

The empirical results reveal that adoption drivers of OPVs as improved maize varieties is influenced by socio-economic and institutional factors. The study results reveal that access to extension services, years spent in school, increase in household income, farm size and perception factor for accepting improved seeds: OPVs contribute positively to the adoption of improved maize varieties. This suggests that any increase in any of the variables will increase the probability of adopting improved maize varieties in order to enhance agricultural output. The improvement in yield will contribute positively to household food security and farm revenue, which are declining, especially in rural areas in African countries. The distance to market and the unavailability of OPVs in local shops were found to adversely affect adoption as farmers were unable to travel such a long distance given that they are located far from town. Additionally, a lack of financial support was the determining factor in purchasing them outside their local markets since they are unavailable to local shops. The adoption of OPVs by smallholder farmers in developing countries will need more than just training to farmers but financial support so that they can be able to purchase required agronomic practices and markets must be developed close to where farmers are located.

\section{Conclusions}

The study investigated the driving factors affecting the adoption of Open-Pollinated Maize Varieties (OPVs) in the study area. This study used a multi-stage random sampling method to collect the data from 150 maize farmers through a face-to-face interview. Descriptive statistics and logit regression were used for analysis purposes. Due to financial reasons and time constraints, the study was limited to three district municipalities that practice maize farming. Farmers use improved maize varieties as means of enhancing their farm outputs and farm returns. The study found that most maize farmers prefer to use the hybrid maize variety than OPVs due to their availability in supermarkets compared to OPVs, which are not readily available. The majority of farmers were female with an average age of 45 years and had a family size of six people who provided family labor. Farmers spent 10 years in school, which means they are literate, allowing them to read and analyze agricultural information. Smallholder farmers had a farm size of 3 ha with an average of 13 years of farming experience. Smallholder maize farmers had access to agricultural extension services and farm organizations, which adopted modern technologies in their farms. The most used improved maize varieties were hybrid, followed by others and OPVs. Smallholder maize farmers were constrained by the high cost of seed variety, non-availability in local shops, lack of knowledge, the high cost of labor, and lack of finances.

In conclusion, female-headed farmers have a low advantage in adopting modern technology as they lack information and access to other agricultural resources. The study agrees with the hypothesis that the driving factors of adoption of improved maize varieties by smallholder maize farmers are socio-economic and institutional factors. Socioeconomic and institutional factors influenced the adoption rate of improved maize varieties (OPVs) in the study area. The study recommends that the government, NGOs, and extension agents must embark on educational training as a strategy to improve farmer awareness and knowledge of OPVs to farmers and increase adoption. The study further recommends that more efforts be made to advise farmers to have other sources of income, apart from 
their social securities from the government, such as small businesses, to overcome the issue of a lack of capital and increase their income. The formation of farm organizations should be encouraged to promote farmer-farmer extension services and knowledge sharing. The study further recommends that further research be conducted in other districts within the province, and this will assist in improving the adoption rate of improved maize varieties.

Author Contributions: M.S., L.M. and A.M. conceived the study idea, co-wrote the paper, and investigated document collection and analysis; L.M. revised software and analysis; M.S. and A.M. revised the paper. All authors have read and agreed to the published version of the manuscript.

Funding: This research received no external funding.

Institutional Review Board Statement: On behalf of the University Research Ethics Committee I hereby grant ethics approval for YUS071SSIG01. This approval is valid for 12 months from the date of approval. Renewal of approval must be applied for BEFORE termination of this approval period. The study was conducted according to the guidelines of the Declaration of Helsinki, and approved by the Institutional Review Board Ethics Committee of University of Fort Hare (1314, 22 August 2018).

Informed Consent Statement: Informed consent was obtained from all subjects involved in the study. Participants were informed about their right to ask questions relating to the research. Confidentiality and privacy was ensured throughout.

Data Availability Statement: Data of this study are available from the corresponding author (M. Sigigaba), upon reasonable request.

Acknowledgments: The authors of this paper sincerely thank the smallholder farmers who made this research a reality by availing themselves to share their knowledge about OPVs and the challenges they faced.

Conflicts of Interest: The authors of this research work declare that they have no conflict of interest regarding the publication of this paper.

\section{References}

1. Danso-Abbeam, G.; Dagunga, G.; Ehiakpor, D.S. Adoption of Zai technology for soil fertility management: Evidence from Upper East region, Ghana. J. Econ. Struct. 2019, 8, 32. [CrossRef]

2. Gebre, G.G.; Isoda, H.; Rahut, D.B.; Amekawa, Y.; Nomura, H. Gender differences in the adoption of agricultural technology: The case of improved maize varieties in southern Ethiopia. Women's Stud. Int. Forum. 2019, 76, 102264. [CrossRef]

3. Da Encarnação Tomo, M.; Zwane, E. Assessment of factors influencing the adoption of improved crop management practices (icmp) by smallholder farmers in the Boane District, Mozambique. S. Afr. J. Agric. Ext. 2020, 48, 99-111. [CrossRef]

4. Fisher, M.; Abate, T.; Alemayehu, Y.; Madulu, R.B. Drought tolerant maize for farmer adaptation to drought in sub-Saharan Africa: Determinants of adoption in eastern and southern Africa. J. Clim. Chang. 2015, 133, 283-299. [CrossRef]

5. Kadafur, I.M.; Idrisa, Y.L.; Shehu, A. Adoption of improved maize varieties in Northern Guinea Savannah of Borno State, Nigeria. J. Agric. Ext. 2020, 24, 34-41. [CrossRef]

6. Chimonyo, V.G.; Mutengwa, C.; Chiduza, C.; Tandzi, L. Participatory variety selection of maize genotypes in the Eastern Cape Province of South Africa. S. Afr. J. Agric. 2019, 47, 103-117. [CrossRef]

7. Kassie, G.T.; Abdulai, A.; Greene, W.H.; Shiferaw, B.; Abate, T.; Tarekegne, A.; Sutcliffe, C. Modeling reference and willingness to pay for drought tolerance (DT) in maize in rural Zimbabwe. World Dev. 2017, 94, 465-477. [CrossRef] [PubMed]

8. Abate, T.; Simtowe, F.; Asfaw, S. Determinants of agricultural technology adoption under partial population awareness: The case of pigeon-pea in Malawi. Agric. Food Econ. 2016, 4, 1-21.

9. La Rovere, R.; Abdoulaye, T.; Kostandini, G.; Guo, Z.; Macrobert, J.; Dixon, J.; Macrobert, J.; Dixon, J. Economic Production, and Poverty Impacts of Investing in Maize Tolerant to Drought in Africa: An ex-ante Assessment. J. Dev. Econ. 2021, 48, 199-225. [CrossRef]

10. Oduniyi, O.S. Climate Change Awareness: A Case Study of Smallcale Maize Farmers in Mpumalanga Province, South Africa. Master's Thesis, University of South Africa, Pretoria, South Africa, 22 November 2013.

11. Katengeza, S.P.; Holden, S.T.; Lunduka, R.W. Adoption of Drought tolerant maize varieties under rainfall stress in Malawi. J. Agric. Econ. 2019, 70, 198-214. [CrossRef]

12. Kakuru, J. Adoption of Drought Tolerant Maize Varieties among Smallholder Maize Farmers in Kamuli and Masindi Districts. Master's Thesis, Makerere University, Makerere, Uganda, 24 January 2019.

13. Fanadzo, M.; Chiduza, C.; van der Stoep, I.; Stevens, J. Crop production management practices as a cause for low water productivity at Zanyokwe Irrigation Scheme. Water SA 2010, 36, 27-36. [CrossRef] 
14. Mahlalela, P.; Blamey, R.; Hart, N.C.; Reason, C.J.C. Drought in the Eastern Cape region of South Africa and trends in rainfall characteristics. J. Clim. 2020, 55, 2743-2759. [CrossRef] [PubMed]

15. Chimonyo, V.G.P.; Mutengwa, C.S.; Chiduza, C. Genotype $\times$ environment interactions and yield stability of stress-tolerant open-pollinated maize varieties in the Eastern Cape Province, South Africa. S Afr. J. Plant Soil 2014, 31, 61-68. [CrossRef]

16. Sibanda, M.; Mushunje, A.; Mutengwa, C.S. An evaluation on the profitability of growing improved maize open pollinated varieties in the Eastern Cape Province, South Africa. J. Dev. Agric. Econ. 2016, 8, 1-13.

17. Chandio, A.A.; Jiang, Y. Factors influencing the adoption of improved wheat varieties by rural households in Sindh, Pakistan. AIMS Agric. Food. 2018, 3, 216-228. [CrossRef]

18. Ali, Z.; Green, R.; Zougmoré, R.B.; Mkuhlani, S.; Palazzo, A.; Prentice, A.M.; Haines, A.; Dangour, A.D.; Scheelbeek, P.F. Long-term impact of West African food system responses to COVID-19. Nat. Food 2020, 1, 768-770. [CrossRef]

19. Nigatu, G.; Mare, Y.; Abebe, A. Determinants of Adoption of Improved (BH-140) Maize Variety and Management Practice, in the Case of South Ari, Woreda, South Omo Zone, SNNPRS, Ethiopia. Int. J. Res. Stud. Biosci. 2018, 6, 35-43.

20. Lunduka, R.W.; Mateva, K.I.; Magorokosho, C. Impact of adoption of drought-tolerant maize varieties on total maize production in South Eastern Zimbabwe. Clim. Dev. 2019, 11, 35-46. [CrossRef]

21. Sibanda, M.; Mushunje, A.; Mutengwa, C.S. Factors influencing the demand for improved maize open pollinated varieties (OPVs) by smallholder farmers in the Eastern Cape Province, South Africa. J. Cereals Oilseeds 2016, 7, 14-26.

22. Sanchez-Toledano, B.I.; Kallas, Z.; Rojas, O.P.; Gil, J.M. Determinant factors of the adoption of improved maize seeds in Southern Mexico: A survival analysis approach. Sustainability 2018, 10, 3543. [CrossRef]

23. Elahi, E.; Abid, M.; Zhang, L.; ul Haq, S.; Sahito, J.G.M. Agricultural advisory and financial services; farm level access, outreach and impact in a mixed cropping district of Punjab, Pakistan. Land Use Policy 2018, 71, 249-260. [CrossRef]

24. Elahi, E.; Weijun, C.; Jha, S.K.; Zhang, H. Estimation of realistic renewable and non-renewable energy use targets for livestock production systems utilising an artificial neural network method: A step towards livestock sustainability. Energy 2019, 183, 191-204. [CrossRef]

25. Elahi, E.; Khalid, Z.; Tauni, M.Z.; Zhang, H.; Lirong, X. Extreme weather events risk to crop-production and the adaptation of innovative management strategies to mitigate the risk: A retrospective survey of rural Punjab, Pakistan. Technovation 2019. [CrossRef]

26. Tran, T.K.V.; Elahi, E.; Zhang, L.; Magsi, H.; Pham, Q.T.; Hoang, T.M. Historical perspective of climate change in sustainable livelihoods of coastal areas of the Red River Delta, Nam Dinh, Vietnam. Int. J. Clim. Chang. Strateg. Manag. 2019, 11, 687-695. [CrossRef]

27. Elahi, E.; Zhang, H.; Lirong, X.; Khalid, Z.; Xu, H. Understanding cognitive and socio-psychological factors determining farmers' intentions to use improved grassland: Implications of land use policy for sustainable pasture production. Land Use Policy 2021, 102, 105250. [CrossRef]

28. Wauters, E.; Mathijs, E. An Investigation into the Socio-psychological Determinants of Farmers' Conservation Decisions: Method and Implications for Policy, Extension and Research. J. Agric. Educ. Ext. 2013, 19, 53-72. [CrossRef]

29. Abid, M.; Scheffran, J.; Schneider, U.A.; Ashfaq, M. Farmers' perceptions of and adaptation strategies to climate change and their determinants: The case of Punjab province, Pakistan. Earth Syst. Dyn. 2015, 6, 225-243. [CrossRef]

30. Mdoda, L.; Obi, A. Analysis of profitability of smallholder irrigated food plots in the Eastern Cape Province of South Africa. J. Agribus. Rural. Dev. 2019, 3, 225-232. [CrossRef]

31. Obi, A.; Ayodeji, B.T. Determinants of economic farm-size-Efficiency relationship in smallholder maize farms in the Eastern Cape Province of South Africa. Agriculture 2020, 10, 98. [CrossRef]

32. Mnkeni, P.N.S.; Chiduza, C.; Modi, A.T.; Stevens, J.B.; Monde, N.; van der Stoep, I.; Dladla, R. Best Management Practices for Smallholder Farming on Two Irrigation Schemes in the Eastern Cape and Kwazulu-Natal through Participatory Adaptive Research (WRC Project No. K5/1477); Water Research Commission: Pretoria, South Africa, 2010; Available online: http:/ /www.wrc.org.za/wpcontent/uploads/mdocs/TT\%20478-10.pdf (accessed on 20 July 2020).

33. Lamontagne-Godwin, J.; Williams, F.; Palitha, W.M.; Bandara, T.; Appiah-kubi, Z. Quality of extension advice: A gendered case study from Ghana and Sri Lanka. J. Agric. Educ. Ext. 2017, 23, 7-22. [CrossRef]

34. Joshi, R.D.; Dhakal, C.K. Predicting Type 2 Diabetes Using Logistic Regression and Machine Learning Approaches. Int. J. Environ. Res. Public Health 2021, 18, 7346. [CrossRef]

35. Lemessa, A.; Gemechu, A. Analysis of factors affecting smallholder farmers' access to formal credit in Jibat District, West Shoa Zone, Ethiopia. Interdiscip. J. Afr. Asian Stud. 2016, 25, 43-53.

36. Kehinde, A.; Adeyemo, R. A Probit analysis of factors affecting improved technologies dis-adoption in cocoa-based farming systems of Southwestern Nigeria. Int. J. Agric. Econ. 2017, 2, 34-41.

37. Katengeza, S.P.; Mangisoni, J.H.; Kassie, G.T.; Sutcliffe, C.; Langyintuo, A.; La Rovere, R.; Mwangi, W. Drivers of improved maize variety adoption in drought prone areas of Malawi. J. Dev. Agric. Econ. 2012, 4, 393-403.

38. Teshom, S.; Tegegne, B. Determinants of Adoption of Improved Teff Varieties by Smallholder Farmers: The Case of Kobo District, North Wollo Zone, Amhara Region, Ethiopia. Int. J. Agric. Econ. 2020, 5, 114-122. [CrossRef]

39. Gidi, L.; Hlongwane, J.; Nkoana, M. Analysing factors limiting the adoption of improved maize varieties by small-scale maize farmers in Ga-Mamadila Village of Polokwane Municipality, Limpopo. In Proceedings of the 5th Annual conference of Agriculture Economics Association of South Africa, Somerset West, South Africa, 25-27 September 2018; pp. 1-11. 
40. Jaleta, M.; Kassie, M.; Marenya, P.; Yirga, C.; Erenstein, O. Impact of improved maize adoption on household food security of maize producing smallholder farmers in Ethiopia. J. Food Sci. 2018, 10, 81-93. [CrossRef]

41. Oluwayemisi, I.A.; Olarinde, L.O.; Fatunbi, A.O. Determinants of adoption of improved maize varieties in Kano-Katsina-Maradi, West Africa. Afr. Crop Sci. J. 2017, 25, 1-11. [CrossRef]

42. Mutanyagwa, A.P. Smallholder Farmers Preferences for Improved Maize Seeds Varieties in Tanzania. Master's Thesis, Sokoine University, Morogoro, Tanzania, 24 March 2017.

43. Subedi, S.; Ghimire, Y.N.; Devkota, D. Socio-economic assessment on maize production and adoption of open pollinated improved varieties in Dang, Nepal. Field Crop Res. 2017, 3, 17-27. [CrossRef]

44. Ketema, M.; Kebede, D. Adoption intensity of inorganic fertilizers in maize production: Empirical evidence from smallholder farmers in Eastern Ethiopia. J. Agric .Sci. 2017, 9, 124-132. [CrossRef] 